\title{
English Plantain Pollen IgG Measurement
}

National Cancer Institute

\section{Source}

National Cancer Institute. English Plantain Pollen Ig G Measurement. NCI Thesaurus.

Code C130086.

A measurement of the English plantain (Plantago lanceolata) pollen Ig $\mathrm{G}$ in a biological specimen. 